Pak. j. sci. ind. res. Ser. A: phys. sci. 201255 (1) 14-20

\title{
Antioxidant Activity Directed Isolations from Punica granatum
}

\author{
Shahina Naz*, Rahmanullah Siddiqi, Syed Muhammad Ghufran Saeed and Syed Asad Sayeed \\ Department of Food Science \& Technology, University of Karachi, Karachi-75270, Pakistan
}

(received April 12, 2010; revised August 19, 2011; accepted August 26, 2011)

\begin{abstract}
The extracts derived from pomegranate juice following antioxidant activity directed isolation were screened for their antioxidant activity through their ability to scavenge 2,2- diphenyl-1-picrylhydrazyl (DPPH) radicals. Only fractions which exhibited $>50 \%$ DPPH scavenging effect at each step of isolation were selected for further purification and their ability to reduce peroxide formation (peroxide value) in heated corn oil. Phytochemical analysis of the pure compounds finally obtained, revealed the presence of pelargonidin-3-galactose (Pg-3-galactose), cyanidin-3-glucose (Cy-3-Glucose), gallic acid, quercetin and myricetin in the fractions exhibiting $>50 \% \mathrm{DPPH}$ scavenging potential. The order of antioxidant activity of these pure compounds by DPPH method was found to be gallic acid $>$ quercetin $>$ myricetin $>\mathrm{Cy}$-3-galactose $>$ Pg-3-Glucose while order with respect to reduction in peroxide value $(\mathrm{PV})$ was the reverse of $\mathrm{DPPH}$.
\end{abstract}

Keywords: Punica granatum, antioxidant activity, pelargonidin-3-galactose, cyanidin-3glucose, gallic acid, quercetin, myricetin

\section{Introduction}

The excess production of active oxygen species, such as $-\mathrm{OH}, \mathrm{O}_{2}$, singlet oxygen and other free radicals, causes damage throughout the cell by oxidizing a variety of molecules, including unsaturated lipids. Lipids are major membrane components and their oxidation leads to significant changes in membrane properties. These changes initiate processes leading to carcinogenesis, mutagenesis, aging and arteriosclerosis (Cutler, 1992; Stadtman, 1992; Pryor, 1986). Free radicals are also involved in the deterioration of food and oil (Naz et al., 2008; 2005; 2004). Cells have limited possibilities for eradicating free radicals, hence it is believed that endogenous antioxidants enhances its ability to protect vital biological functions (Osawa et al., 1990; Kohen et al., 1988; Cutler, 1984). There is an increasing interest in the application of naturally occurring antioxidants as therapeutic agents. Fruit and vegetable antioxidants play an important role in reducing the risk of degenerative diseases such as cardiovascular disease and various cancers and neurological diseases (Ames et al., 1993). Ascorbate is the most studied antioxidant vitamin for its role in reducing the risk of degenerative diseases (Fraga et al., 1991). However, recent studies have shown that fruit and vegetable total phenolics and anthocyanins contribute more to the antioxidant capacity than ascorbate (Connor et al., 2002; Kang and Saltveit, 2002; Deighton et al., 2000; Kalt et al., 1999).

*Author for correspondence; E-mail: naz.shahina@yahoo.com
Pomegranate fruit, which contains a high proportion of polyphenolic compounds (gallocatechins, delphinidin, cyanidin and pelargonidin) is very well known for its therapeutic uses. Pomegranate juice and peel provide protection against hepatotoxicity (Murthy et al., 2002), methicillin-resistant Staphylococcus aureus (Machado et al., 2002), Human Immunodeficiency Virus (HIV) (Lee and Watson, 1998), genital herpes virus (Zhang et al., 1995) and tumors (Boukharta et al., 1992). They exhibit estrogen like activity (Maru et al., 2001), reduce systolic blood pressure (Aviram and Dornfeld, 2001), and decrease Low Density Lipoprotein (LDL) susceptibility to aggregation and retention (Aviram et al., 2000). They also exhibit strong antioxidant potential against lipid peroxidation, LDL and High Density Lipoprotein (HDL) oxidation, which justifies their use as anti atherosclerotic agent and as biopreservative in food (Plumb et al., 2002, Aviram, 2002; Singh et al., 2002; Aviram and Dornfeld, 2001). Pomegranate extract exhibits antienzymic activity against glycosyl transferase (Oshima and Mitsunaga, 1999), collagenase (Kawakami, 1995) and also activity against eicosanoid (Schubert et al., 1999). Due to being a collagenase inhibitor, pomegranate extract has been successfully used in skin cosmetics.

In view of its high medicinal potential and previous findings, the study was designed to isolate various fractions from the fruit following antioxidant activity 
so that its further possible uses in medicines, therapeutics and food preservation could be determined.

\section{Materials and Methods}

Antioxidant activity guided isolation. Juice of $5 \mathrm{~kg}$ of pomegranate was extracted with the help of a juice extractor machine. The juice was concentrated on a rotary evaporator at $37^{\circ} \mathrm{C}$. The crude juice after screening for antioxidant activity was separated by column chromatography. A column $(100 \times 3.5 \mathrm{~cm})$ containing cellulose of mesh size 40 was used. The cellulose was soaked in a conical flask for $4 \mathrm{~h}$ in mobile phase-acetic acid: hydrochloric acid: water (30:3:10). The mixture was degassed and was poured into the column taking all the precautions to avoid the incorporation of the air. The column was left overnight for perfect settling of the particles. The extracted and dried sample of juice $(200 \mathrm{~g})$ was resolved using a flow rate of $1 \mathrm{~mL} / \mathrm{min}$. The five coloured bands (PG1, PG2, PG3, PG4 and PG5 separated within $6 \mathrm{~h}$ ) were obtained using a fraction collector. When the fractions were screened for their antioxidant activities, PG1 and PG3 were found to be substantially active. For further separation of PG1 ( $39 \mathrm{~g})$, flash chromatography was used. For this purpose a column $(20 \times 2.5 \mathrm{gm})$ filled with silica of mesh size 360 was used and the flow rate of the mobile phase butanol : acetic acid : water, 4:1:5 (BAW) was adjusted at a rate of $1 \mathrm{~mL} / \mathrm{min}$. The fractions obtained were dried using rotary evaporator. The fractions PG1b and PG1c which showed significant antioxidant activity were purified further.

The dried PG1b fraction (12 g) was purified by paper chromatography, BAW was used as solvent system. The bands separated after 22-24 h on chromatographic paper were cut into small pieces and the fractions PG1b1, PG1b3 and PG1b4 were recovered by soaking the pieces in methanol:HC1 (99:1) with constant stirring for 2-3 $\mathrm{h}$. Each fraction was filtered and dried on rotary evaporator at room temperature and tested for antioxidant activity. The fractions, PG1b1(1.56 g) and PG1b2 (1.2 g), which showed appreciable antioxidant activity were further purified by Thin Layer Chromatography (TLC) using silica gel as stationary and BAW as mobile phase. The fractions eluted from preparative TLC were resolved on High Performance Thin Layer Chromatography (HPTLC) using BAW. The purity of the fractions was confirmed by High Performance Liquid Chromatography (HPLC) using $\mu$-BondaPak C-18 column $(125 \mathrm{~A}, 10 \times 3.9 \times 30 \mathrm{~mm})$ using a mixture of methanol:acetic acid:water (71:7:22). Identification of the pure compounds was carried out in 99:1 methanolic $\mathrm{HCl}$ on a UV-visible spectrophotometer at 200-600 nm. Since the compounds were identified as anthocyanins, they were also analyzed for their carbohydrate and organic acid moieties.

The fraction PG1c was evaporated to $1 / 10$ of its original volume in a rotary evaporator at $40{ }^{\circ} \mathrm{C}$, acidified with $2 \mathrm{M} \mathrm{H}_{2} \mathrm{SO}_{4}$ and then extracted with chloroform. The chloroform extract was dried (6.8 g) and then analyzed by TLC-silica using chloroform-acetic acid (9:1) as mobile phase. Among the fractions- PG1c1 and PG1c2, only PG1c1 (1.66 g) showed antioxidant potential. The fraction was scratched from the plates, dissolved in methanol:acetone $(75: 25)$, dried, washed with methanol and then dried again. The purity of the compounds was confirmed by HPTLC, HPLC and identified using $\mathrm{R}_{\mathrm{f}}$ values and spectral properties.

PG3 (6.3 g) was further fractionated into PG3a (117 mg) and PG3b (121mg) in the same way as PG1c1 and PG1c2 from PG1c. Purity was checked by two dimensional chromatography, HPTLC, and HPLC. Purified compounds were finally run in BAW analyzed in UV and UV + ammonia, and scanned in UV-visible region in ethyl alcohol for $\lambda_{\text {max }}$ for identification.

Determination of carbohydrate moiety. The purified compound ( $2 \mathrm{mg}$ ) was hydrolyzed in a mixture of $2.5 \mu \mathrm{L}$ of methanol and $2 \mathrm{~N} \mathrm{HCl}$ on a boiling water bath for 30 min (Markham, 1982). The mixture was cooled down to room temperature. The aglycone was extracted in $5 \mu \mathrm{L}$ of amyl alcohol in a separating funnel. After shaking continuously, the upper layer of amyl alcohol was collected. The lower layer containing hydrolyzed sugar was washed with a small quantity of $10 \%$ di- $n$ octylmethylamine in chloroform to remove $\mathrm{HCl}$, washed with chloroform to remove traces of amines and then dried.

Identification of sugar. Two drops of water were added to the isolated hydrolyzed sugar for preparing a concentrated solution which was spotted on Whatman chromatographic paper 1 with the standard reference sugars and was developed in BAW for $14 \mathrm{~h}$. The developed chromatogram was dried and dipped in aniline-hydrogen phthalate and heated at $110{ }^{\circ} \mathrm{C}$ for 3-5 min to visualize sugar spots (Harborne, 1973). To distinguish between the sugars giving identical colour reactions and $\mathrm{R}_{\mathrm{f}}$ values, a small quantity of sugar was treated with resorcinol-1 $\mathrm{M} \mathrm{H}_{2} \mathrm{SO}_{4}$ and aniline-hydrogen 
phthalate separately and then both of the coloured complexes so formed were scanned in the visible region.

Determination of organic acid moiety. The isolated compound $2 \mathrm{mg}$ was dissolved in $100 \mu \mathrm{L}$ of ethanol and heated boiling water bath for $5 \mathrm{~min}$. The two dimensional paper chromatography was carried out by using the systems- $n$-propanol: IM ammonium hydroxide (7:3) and $n$-butanol:formic acid:water (10:3:10). The chromatogram was dried in order to remove the traces of formic acid and was sprayed with bromothymol blue solution prepared by dissolving $0.04 \mathrm{~g}$ of bromothymol blue in $100 \mathrm{~mL}$ of $0.01 \mathrm{M}$ sodium hydroxide (Harborne, 1973).

Spectroscopy and chromatography. Ultraviolet absorbance, $\lambda_{\max }$ in $\mathrm{nm}$, were measured in methanol, on a Shimadzu 160A UV-Visible spectrophotometer. Merck Silicagel $160 \mathrm{G}_{254}(20 \times 20 \mathrm{~cm})$ glass plates (5715) were used for analytical TLC and MachereyNagel HPTLC Nano-SIL 20 UV $254(0.2$ mm, $10 \times$ $10 \mathrm{~cm}$ ) plates $(811022)$ were used for two dimensional chromatography to confirm the purity of the isolated compounds. HPLC was performed on a Micromeritics instrument equipped with a 787 variable UV-visible detector, a $\mu$-Bondapak ODS $(\mathrm{C}-18,300 \times 4.5 \times 5 \mu \mathrm{m})$ column (Waters) and Chromatography Station for Windows (CSW32). The mobile phase used for HPLC was $50 \%$ aqueous methanol at a flow rate of $1 \mathrm{~mL} / \mathrm{min}$., pressure 8.4 bar and attenuation $0.32 \mathrm{mV}$.

DPPH scavenging activity. Reaction mixtures containing test sample [5 $\mu \mathrm{L}$ dissolved in dimethyl sulphoxide (DMSO)] and $95 \mu \mathrm{L}$ of $316 \mu \mathrm{M}$ ethanolic solution of DPPH in 96-well microtiter plates were incubated at $37^{\circ} \mathrm{C}$ for $30 \mathrm{~min}$ and absorbance was measured at $515 \mathrm{~nm}$ (Yu et al., 2002; Wettasinghe and Shahidi, 2000). Percent inhibition by sample treatment was determined by comparison with a DMSO-treated control group.

Peroxide radical scavenging activity in oil. Ten grams of fresh oil were taken into two clean and dry flasks separately (control and test). In one of them $0.1 \mathrm{~g}$ of the test sample was added (Test). Both were heated at $98^{\circ} \mathrm{C}$ under carefully controlled aerated conditions for 2-3 h. At the end of heating, the peroxide value of each was determined after cooling the flasks to ambient room temperature (Kochhar and Rossell, 1990; Kahl and Hildebrandt, 1986).

Determination of Peroxide Value (PV). The test was carried out in diffused daylight. One gram of oil sample from control and test were dissolved separately in $10 \mathrm{~mL}$ of chloroform in an iodine flask by stirring. $15 \mathrm{~mL}$ of acetic acid and $1 \mathrm{~mL}$ of saturated potassium iodide solution were then added. The flasks were stoppered quickly, shaken for one min and then, kept in the dark for $5 \mathrm{~min}$. After adding $75 \mathrm{~mL}$ distilled water, the liberated iodine was titrated with sodium thiosulphate solution using starch solution as an indicator. A blank test was carried out simultaneously without oil sample under the same conditions (IUPAC Standard Methods, 2.501, 1987).

\section{Results and Discussion}

The fractions isolated and their antioxidant activities have been depicted in the antioxidant activity directed isolation scheme (Fig.1). Flash chromatography of PG1 lead to the isolation of PG1b1, PG1b2, PG1b3 and PG1b4. The fractions could not be studied further due to their unstable character and immediate decolourization. PG1bl and PG1b2 which were further purified by TLC and identified as anthocyanins in view of their chromatographic and other properties. The purified compound from PG1b1 was identified as pg-3galactose and from PG1b2 was identified as Cy3glucose after comparing their $\mathrm{R}_{\mathrm{f}}$ and spectral values with the standard compounds supplied by Fluka. Carbohydrate moieties -galactose and glucose were identified on the basis of a brownish coloured spot with aniline-hydrogen phthalate and comparison of their $R_{f}$ values $\left(R_{f}\right.$ value was 0.12 for both galactose and glucose) with the standard sugars. On the basis of $R_{f}$ values in BAW, galactose and glucose were distinguished. Glucose showed two peaks at 489 and $555 \mathrm{~nm}$ with an inflection at $430 \mathrm{~nm}$ while galactose showed peaks at 422 and $495 \mathrm{~nm}$ with an inflection at $550 \mathrm{~nm}$ on treatment with resorcinol- $1 \mathrm{M} \mathrm{H}_{2} \mathrm{SO}_{4}$. No organic acid moiety attached to the purified anthocyanin was detected as confirmed by the absence of a shoulder peak at $334 \mathrm{~nm}$ (Horry and Jay, 1988) (Table 1). The pure compounds from fractions PG3a and PG3b and PG1c2 were identified as quercetin, myricetin and gallic acid, respectively in view of their chromatographic and spectral properties compared to standards (Table 2).

The order of antioxidant activity of these pure compounds by DPPH method was found to be gallic acid $>$ quercetin $>$ myricetin $>$ Cy-3-galactose $>$ Pg-3 Glucose (Fig. 2), while the order with respect to reduction in $\mathrm{PV}$ was the reverse of DPPH (Fig. 3). In general, the antioxidant capacity of 
compounds possessing an $o$-diphenolic arrangement (catechol structure) is higher than in monophenols due to their ability to form $o$-quinones when reacting with free radicals. Replacing the 3-hydroxyl group of protocatechuic acid by a methoxy group as in vanillic acid had a suppressive influence on the antioxidant capacity (Rosch et al., 2003). This explains the comparatively higher anti-oxidant capacity of cyanidin compared to pelargonidin. This is also in

Table 1. Spectral and chromatographic properties of the isolated anthocyanins

\begin{tabular}{|c|c|c|}
\hline \multirow[t]{2}{*}{ Criterion } & \multicolumn{2}{|c|}{ Property recorded } \\
\hline & Pelargonidin-3-galactose & Cyanidin-3-glucose \\
\hline Colour & Orange red & Deep red \\
\hline$(\mathrm{Rf} x 100)$ in BAW & 0.46 & 0.67 \\
\hline $\begin{array}{l}\text { Two dimension } \\
\text { chromatography } \\
\text { BAW and } 5 \% \text { aqueous } \\
\text { acetic acid }\end{array}$ & Best separation & Best separation \\
\hline Acid/Base response & $\begin{array}{l}\text { Blue/colourless in base and } \\
\text { red in acidic medium }\end{array}$ & $\begin{array}{l}\text { Blue/colourless in } \\
\text { base and red in acidic } \\
\text { medium }\end{array}$ \\
\hline Carbohydrate moiety & $\begin{array}{l}\text { Galactose: } \\
\mathrm{R}_{\mathrm{f}} 0.12 \text {, brown spot with } \\
\text { aniline-hydrogen phthalate, } \\
\text { Peaks at } 422 \text { and } 495 \mathrm{~nm} \\
\text { when complexed with } \\
\text { resorcinol- } 1 \mathrm{M} \mathrm{H}_{2} \mathrm{SO}_{4}\end{array}$ & $\begin{array}{l}\text { Galactose: } \\
\mathrm{R}_{\mathrm{f}} 0.14 \text {, brown spot } \\
\text { with aniline-hydrogen } \\
\text { phthalate, Peaks at } 489 \\
\text { and } 555 \mathrm{~nm} \text { when complexed } \\
\text { with resorcinol-1 } \mathrm{M} \mathrm{H}_{2} \mathrm{SO}_{4}\end{array}$ \\
\hline Organic acid moiety & No organic acid moiety & No organic acid moiety \\
\hline $\begin{array}{l}\lambda_{\max } \text { in } \mathrm{HCl} \text {-methanol and } \\
\text { then in } 5 \% \text { alcoholic } \mathrm{AlCl}_{3}\end{array}$ & $\begin{array}{l}523 \mathrm{~nm} \text {, no bathochromic } \\
\text { shift as there is no catechol } \\
\text { group in the molecule } \\
\text { group in the molecule }\end{array}$ & $\begin{array}{l}523 \mathrm{~nm}, \text { a } \\
\text { bathochromic shift was } \\
\text { observed due to catechol }\end{array}$ \\
\hline
\end{tabular}

Table 2. Spectral and chromatographic properties of the isolated flavonols

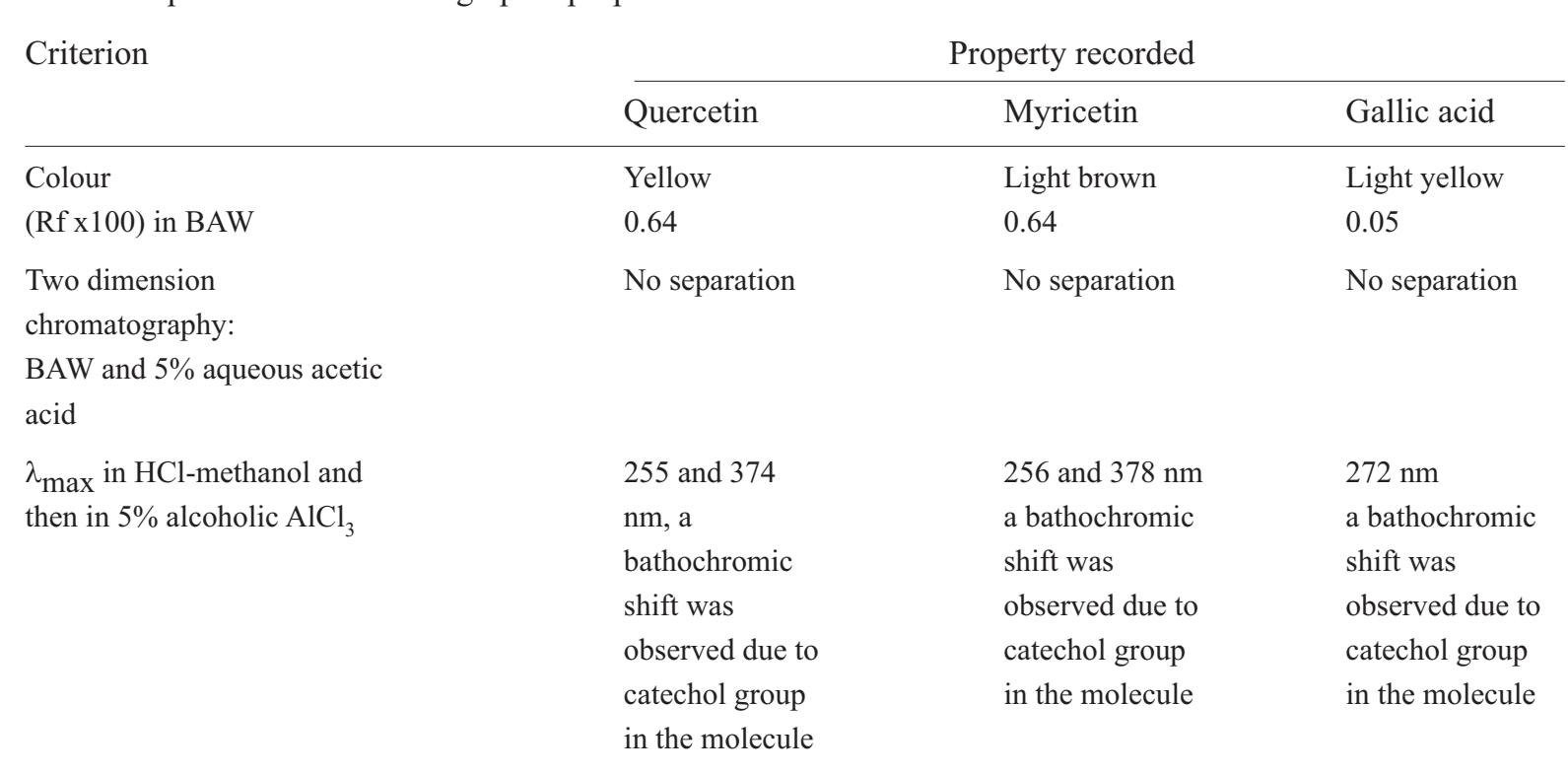




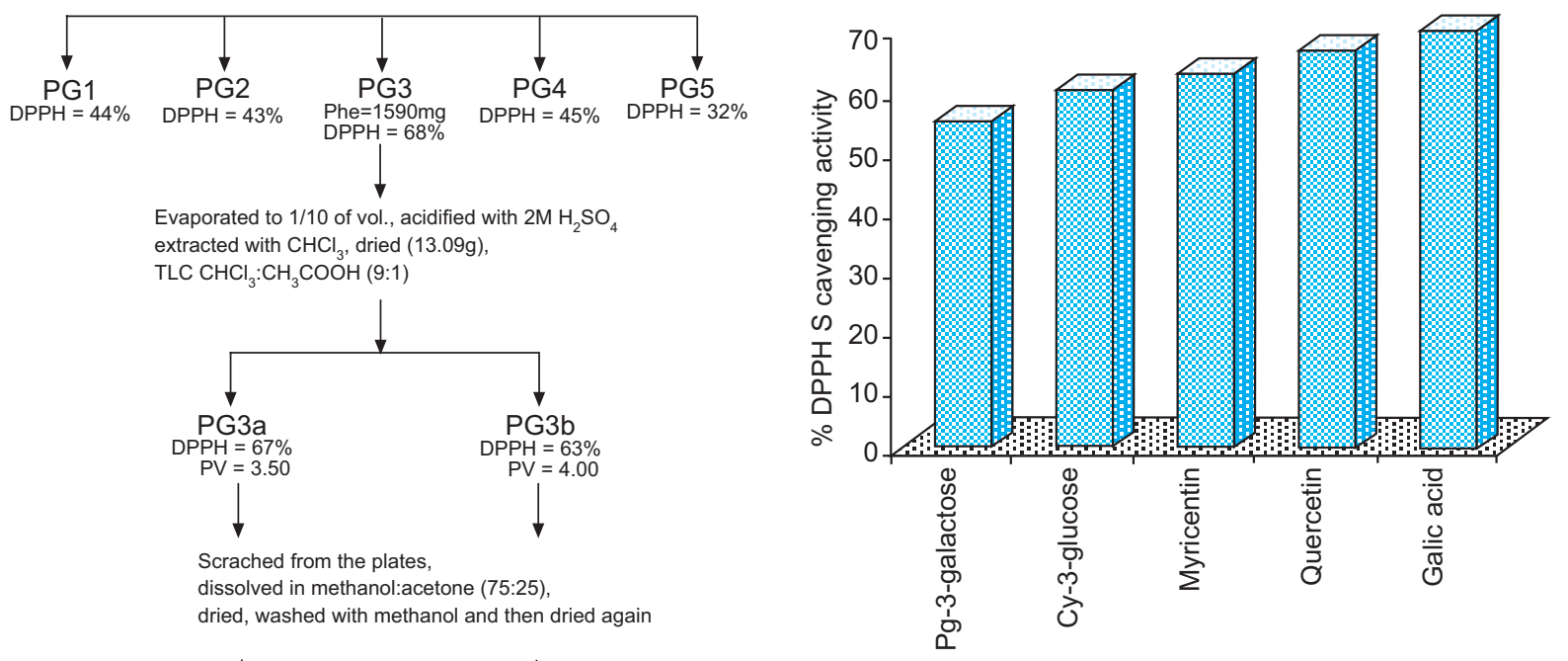

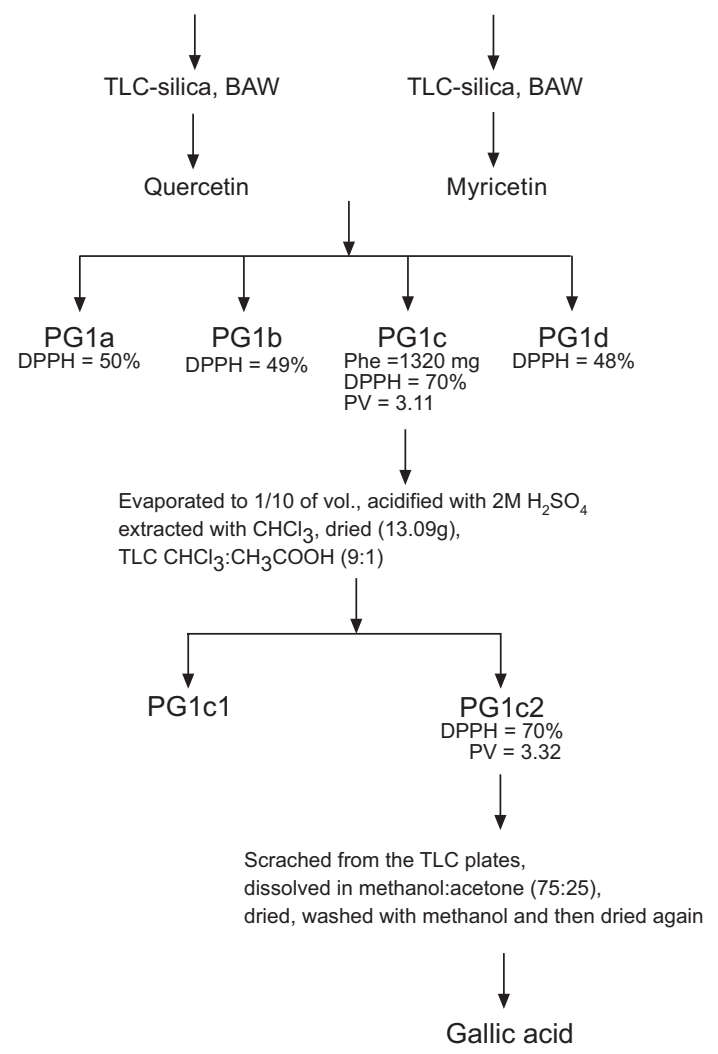

Fig. 1. Scheme for antioxidant activity directed isolations from pomegranate juice.

agreement with the findings of Noda et al. (2002) in which free radical scavenging activity of $70 \%$ active extract of pomegranate was determined and $\mathrm{ID}_{50}$ of cyanidin $(22 \mu \mathrm{M})$ against $\mathrm{O}_{2}$ - was found to be less than pelargonidin $(45 \mu \mathrm{M})$. The highest antioxidant activity of gallic acid is due to the presence of an additional hydroxyl group. Because of its pyrogallol structure, it shows a greater oxidizability and the quinine formed can be stabilized by resonance structures. The importance of a pyrogallol
Fig. 2. Relative \% DPPH scavenging activity of the isolated compounds.

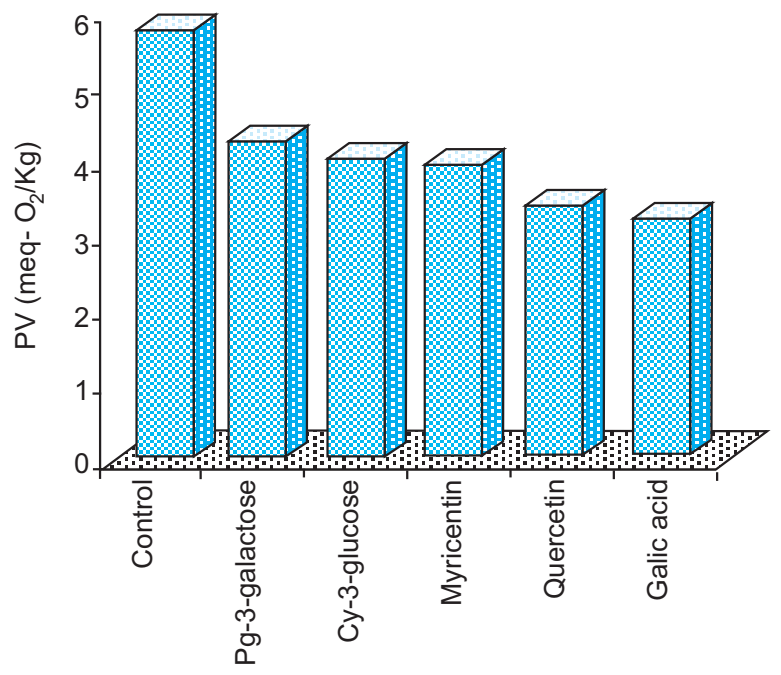

Fig. 3. Effect of the isolated compounds on the PV of the heated oil.

structure for maximum antioxidant activity of hydroxyl benzoic acid derivatives was also described by (RiceEvans et al., 1996) for the TEAC assay and by Cao et al. (1997) for the ORAC assay. A possible reason for the lower antioxidant activity of myricetin compared to quercetin could be the high oxidation sensitivity of myricetin which caused its rapid decomposition during measurement (Burda and Oleszek, 2001).

\section{Acknowledgement}

This research study was financially supported by the Karachi University's Scholarship Fund and the Dean of Science Research Grant. 


\section{References}

Ames, B.M., Shigena, M.K., Hagen, T.M. 1993. Oxidants, antioxidants and the degenerative diseases of aging. Proceedings National Academy of Sciences, USA, 90: 7915-7922.

Aviram, M. 2002. Pomegranate juice as a major source for polyphenolic flavonoids and its most potent antioxidant against LDL oxidation and atherosclerosis. Free Radical Research, 36: 71-72.

Aviram, M., Dornfeld, L. 2001. Pomegranate juice consumption inhibits serum angiotensin converting enzyme activity and reduces systolic blood pressure. Atherosclerosis, 158: 195-198.

Aviram, M., Dornfeld, L., Rosenbalt, M., Volkova, N., Kaplan, M., Coleman, R., Hayek, T., Presser, D., Fuhrman, B. 2000. Pomegranate juice consumption reduces oxidative stress, atherogenic modifications to LDL, and platelet aggregation studies in humans and in atherosclerotic apolipoprotein E-deficient mice. American Journal of Clinical Nutrition, 71: 10621076.

Boukharta, M., Jalbert, G., Castonguoy, A. 1992. Efficacy of ellagitannins and ellagic acid as cancer chemopreventive agents. Bulletin Liaision-Groupe Polyphenols, 16: 245-249.

Burda, S., Oleszek, W. 2001. Antioxidant and antibacterial activities of flavonoids. Journal of Agricultural and Food Chemistry, 49: 2774-2779.

Cao, G., Sofie, E., Prior, R.L. 1997. Antioxidant and pro oxidant behavior of flavonoids: Structureactivity relationship. Free Radical Biology and Medicine, 22: 749- 760.

Connor, A.M., Luby, J.J., Hancock, J.F., Berkheimer, S., Hanson, F.J. 2002. Changes in fruit antioxidant activity among blueberry cultivars during coldtemperature storage. Journal of Agricultural and Food Chemistry, 50: 893-898.

Cutler, R.G. 1992. Genetic stability and oxidative stress. In: Free Radicals and Aging. I. Emerit and B. Chance (eds), pp. 31-46, Birkhauser Verlag, Basel, Switzerland.

Cutler, R.G. 1984. Antioxidants, aging, and longevity. In: Free Radicals in Biology. W.A. Pryor (ed.), vol. VI, pp. 371-423, Academic Press, Orlando, FL, USA.

Deighton, N., Brennan, R., Finn, C., Davies, H.V. 2000. Antioxidant properties of domesticated and wild Rubus species. Journal of the Science of Food and Agriculture, 80: 1307-1313.
Fraga, C.G., Motchink, P.A., Shigenaga, M.K., Helbock, H.J., Jacob, R.A., Ames, B.N. 1991. Ascorbic acid protects against endogenous oxidative DNA damage in human sperm. Proceedings National Academy of Sciences, USA, 88: 11003-11006.

Harborne, J.B. 1973. Phytochemical Methods, 63 pp., Chapman and Hall, London, UK.

Horry, J.P., Jay, M. 1988. Distribution of anthocyanins in wild and cultivated banana varieties. Phytochemistry, 27: 2667-2672.

IUPAC 1987. Standard Methods for the Analysis of Oils, Fats and Derivatives. Determination of the Peroxide Value, Method 2.501, 7th edition, 199 pp., Alden Press, Oxford, UK.

Kalt, W., Fomey, C.F., Martin, A., Prior, R.L. 1999. Antioxidant capacity, vitamin $\mathrm{C}$, phenolics, and anthocyanins after fresh storage of small fruits. Journal of Agricultural and Food Chemistry, 47: 4638-4644.

Kang, H.-M., Saltveit, M.E. 2002. Antioxidant capacity of lettuce leaf tissue increases after wounding. Journal of Agricultural and Food Chemistry, 50: 7536-7541.

Kawakami, A. 1995. Extraction of collagenase inhibitor from plants for therapeutic use and for manufacturing skin cosmetics. Japanese Kokai Tokkyo Koho, JP 07: 526.

Khal, R., Hildebrandt, A.G. 1986. Methodology for studying antioxidant activity and mechanisms of action of antioxidants. Food and Chemical Toxicology, 24: 1007-1014.

Kochhar, S.P., Rossell, J.D. 1990. Detection, estimation and evaluation of antioxidants in food systems. In: Food Antioxidants, B.J.F. Hudson (ed.), pp. 19-64, Elsevier, London, UK.

Kohen, R., Yamamoto, Y., Cundy, K.C., Ames, B.N. 1988. Antioxidant activity of carnosine, homocamosine, and anserine present in muscle and brain. Proceedings National Academy of Sciences, USA, 85: 3175-3179.

Lee, J., Watson, R.R. 1998. Pomegranate: a role in health promotion and AIDS? In: Nutrition, Foods and AIDS, R. R. Watson (ed.), pp. 213-216, CRC Press, Boca Roton, FL, USA.

Machado, T.D.B., Leal, I.C.R., Amaral, A.C.F ., Dos Santos, K.R.N., Da Silva, M.G., Kuster, R.M. 2002. Antimicrobial ellagitannin of Punica granatum fruits. Journal of Brazilian Chemical Society, 13: 606-610.

Markham, K.R. 1982. Techniques of flavonoid identification. In: Hydrolysis and the Analysis of 
Glycosides, pp. 52-57, Academic Press, London, UK. Maru, I., Ohnishi, J., Yamagushi, S., Oda, Y., Kakehi, K., Ohta, Y. 2001. An estrogenlike activity in pomegranate juice. Nippon Shokuhin Kagaku Kogaku Kaishi, 48: 146-149.

Murthy, K.N.C., Jayaprakasha, G.K., Saogh, R.P. 2002. Studies on antioxidant activity of pomegranate (Punica granatum) peel extract using in vivo models. Journal of Agricultural and Food Chemistry, 50: 4791-4795.

Naz, S., Siddiqi, R., Sayeed, S.A. 2008. Effect of flavonoids on the stability of corn oil. International Journal of Food Science \& Technology, 43: 1850-1854.

Naz, S., Sheikh, H., Siddiqi, R., Sayeed, S.A. 2005. Deterioration of olive, corn and soybean oils due to air, light, heat and deep-frying. Food Research International, 38: 127-134.

Naz, S., Sheikh, H., Siddiqi, R., Sayeed, S.A. 2004. Oxidative stability of olive, corn and soybean oil under different conditions. Food Chemistry, 88: 253-259.

Noda, Y., Kaneyuki, T., Mori, A. and Packer, L. 2002. Journal of Agricultural and Food Chemistry, 50: 166-171.

Osawa T., Namiki, M., Kawakishi, S. 1990. Role of dietary antioxidants protection against oxidative damage. In: Antimutagenesis and Anticarcinogenesis Mechanism II, Y. Kuroda, D.M. Shankel \& D. Waters (eds.), pp. 139-153, Plenum Press, New York, USA.

Oshima, K., Mitsunaga, T. 1999. Glucosyl transferase inhibitors from plant extracts for dentifrice. Japanese Kokai Tokkyo Koho, JP 11: 247.

Plumb, G.W., De Pascual-Teress, S., Santos-Buelga, C., Rivas-Oonzalo, J.C.,Williamson, G. 2002. Antioxidant properties of gallocsatechin and prodelphinidins from pomegranate peel. Redox Report, 7: 41-46.
Pryor, W.A. 1986. Cancer and free radicals. In: Antimutagenesis and Anticarcinogenesis Mechanism, D.M. Shankel, P.E. Hartman, T, Kada \& A. Hollaender (eds.), pp. 45-59, Pleum Press, New York, USA.

Rice-Evans, C.A., Nicholas J.M., George, P. 1996. Structure-antioxidant activity relationships of flavonoids and phenolic acids. Free Radical Biology and Medicine, 20: 933-956.

Rosch, D., Bergmann, M., Knorr, D. 2003. Structureantioxidant efficacy relationships of phenolic compounds and their composition to the antioxidant activity of Sea Buckthorn juice. Journal of Agriculture and Food Chemistry, 51: 4233-4239.

Schubert, S.Y., Lansky, E.P., Neeman, I. 1999. Antioxidant and eicosanoid enzyme inhibition properties of pomegranate seed oil and fermented juice flavonoids. Journal of Ethnopharmacology, 66: 11-17.

Singh, R.P., Murthy, K.N.C., Jayaprakasha, O.K. 2002. Studies on the antioxidant activity of pomegranate (Punica granatum) peel and seed extracts using in vitro models. Journal of Agricultural and Food Chemistry, 50: 81-86.

Stadtman, E.R. 1992. Protein oxidation and aging. Science, 257: 1220-1224.

Wettasinghe, M., Shahidi, F. 2000. Scavenging of reactive-oxygen species and DPPH free radicals by extracts of borage and evening primrose meals. Food Chemistry, 70: 17-26.

Yu, L., Haley, S., Perret, J., Harris, M., Wilson, J., Qian, M. 2002. Free radical scavenging properties of wheat extract. Journal of Agricultural and Food Chemistry, 50: 1619-1624.

Zhang, J., Zhan, B., Yao, X., Song, J. 1995. Antiviral activity of tannin from the pericarp of Punica granatum L. against herpes virus in vitro. Zhongguo Zhongyao Zazhi, 20: 556-558. 